Gelenkschmerzen und -schwellungen

\section{Was ist das für ein Tumor im Zeh?}

Ein 39-jähriger Patient stellte sich mit einer erheblichen, schmerzhaften Schwellung des Mittelgelenks des rechten zweiten Zehs vor. Diese bestand seit ca. sechs Jahren und hatte in der letzten Zeit massiv zugenommen. Anamnestisch bekannt waren eine Sarkoidose und eine Hyperurikämie, die seit ca. zwei Jahren mit $300 \mathrm{mg} / \mathrm{d}$ Allopurinol therapiert wurde. Aufgrund der durch die Sarkoidose und Gelenkbeschwerden verursachten Behinderungen war eine Frühberentung erfolgt.

— Die Laboruntersuchung ergab folgende Auffälligkeiten: Pathologisch erhöht waren Harnsäure (10,2 mg/ dl), $y$-GT (72 U/l), Kreatinin (1,49 mg/dl), Harnstoff $(49,0$ $\mathrm{mg} / \mathrm{dl}$ ), Gesamt Cholesterin (202 mg/dl), Triglyzeride ( 253 $\mathrm{mg} / \mathrm{dl}$ ); erniedrigt waren GFR (glomeruläre Filtrationsrate, $56 \mathrm{ml} / \mathrm{min}$ ) und HDL-Cholesterin (39 mg/dl).

Das MRT des rechten Vorfußes zeigte mehrere weichteiIdichte Tumoren jeweils streckseitig gelegen, hufeisenförmig die Zehen umgebend, am ausgeprägtesten am Mittelglied der zweiten Zehe. (Abb. 1 und 2). Aufgrund der multifokalen Lokalisation konnte ein malignes Geschehen weitgehend ausgeschlossen werden.

Um eine sichere Diagnose stellen zu können, wurde eine operative Exzision durchgeführt. Bei dem Exzisat von kreideartiger Konsistenz (Größe: 3,5 x 2,4 x 1,5 cm) der zweiten Zehe rechts handelte es sich um einen Gichttophus. Trotz Ernährungsumstellung und Therapie mit Allopurinol in maximaler Dosierung konnte die Hyperurikämie nicht ausreichend behandelt werden. Deshalb wurde die Behandlung auf Febuxostat $80 \mathrm{mg} / \mathrm{d}$ umgestellt. Nach vier Monaten lag der Harnsäurewert bei $5,1 \mathrm{mg} / \mathrm{dl}$, weitere drei Monate später wurde ein Harnsäurewert von 4,5 mg/ dl gemessen. Mit der Normalisierung der Harnsäurewerte bildeten sich auch die noch vorhandenen Gichttophi und die damit verbundenen Gelenkschmerzen zurück (Abb. 3), sodass der Patient sogar wieder in der Lage war, Sport zu treiben. Dies wiederum führte zur Gewichtsreduktion von initial $113 \mathrm{~kg}$ auf $80 \mathrm{~kg}$.
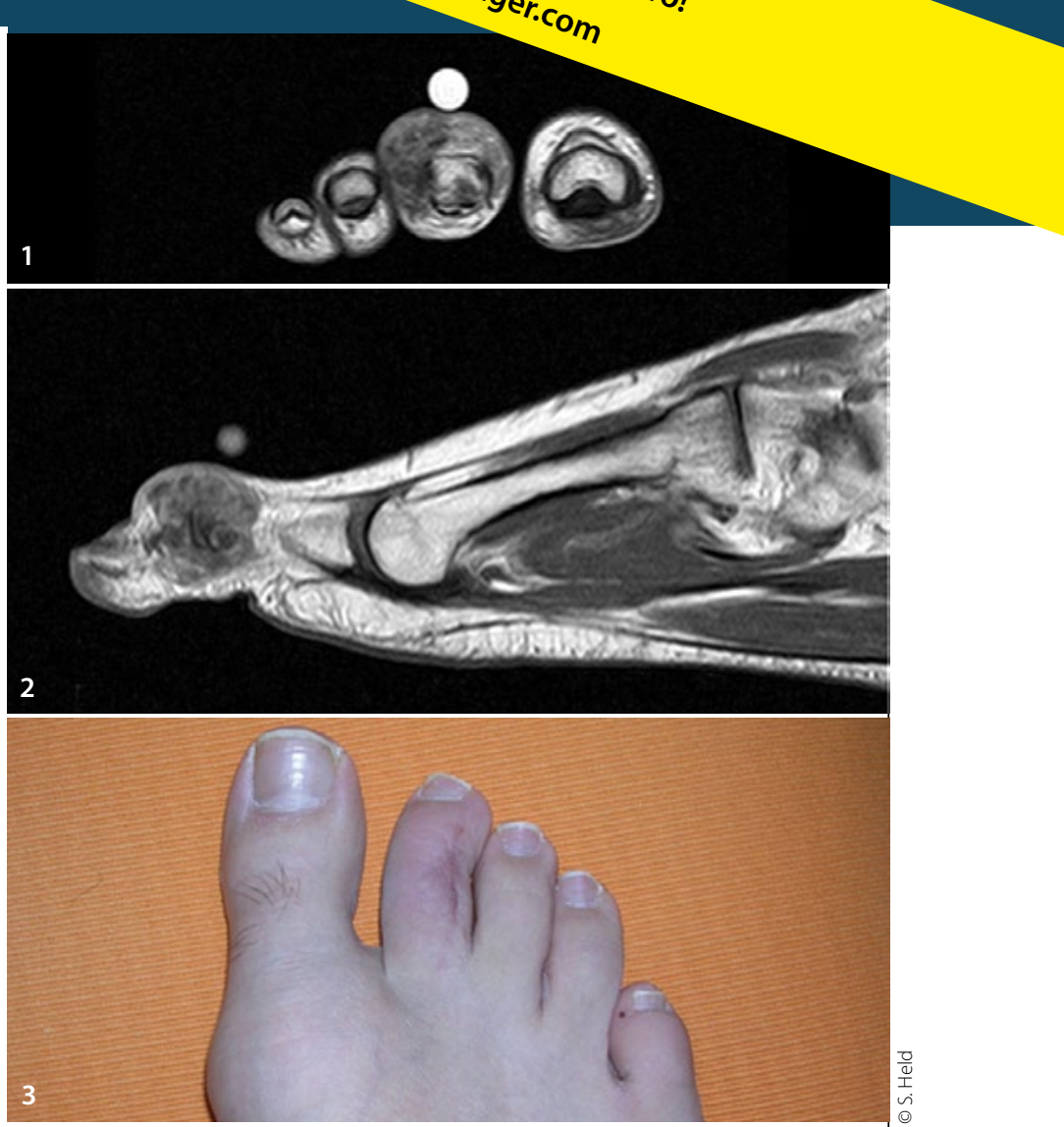

Bei unserem Patienten konnte trotz mehrjähriger Therapie mit Allopurinol in maximaler Dosierung keine ausreichende Senkung des Serum-Harnsäurewerts erzielt werden. Erst die Umstellung auf eine Medikation mit Febuxostat bewirkte innerhalb kurzer Zeit eine Reduktion der Harnsäurewerte unter den empfohlenen Richtwert von $6 \mathrm{mg} / \mathrm{dl}$. Gleichzeitig konnte eine Rückbildung der bereits multifokal lokalisierten, schmerzhaften Gichttophi im Bereich des rechten Vorfußes beobachtet werden. Diese Effekte hielten über die gesamte Therapiedauer an. Auch der Allgemeinzustand des Patienten verbesserte sich deutlich.

Keywords: Hyperuricemia, gout tophi, febuxostat, case report, gout

- Dr. med. Stephan Held, Facharzt für Allgemeinmedizin/Geriatrie, Gemeinschaftspraxis am Lohmannshof, Akademische Lehrpraxis der Universität Münster, Kreuzbergerstr. 2, D-33619 Bielefeld

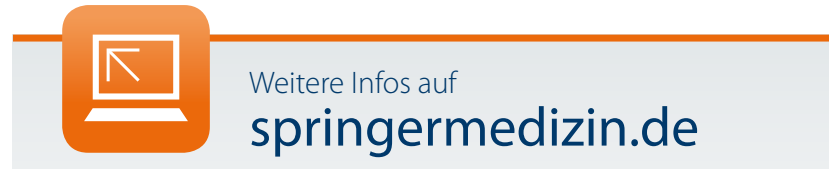

Weitere Fälle unserer Leser finden Sie im Internet unter: - www.springermedizin.de/blickdiagnose 